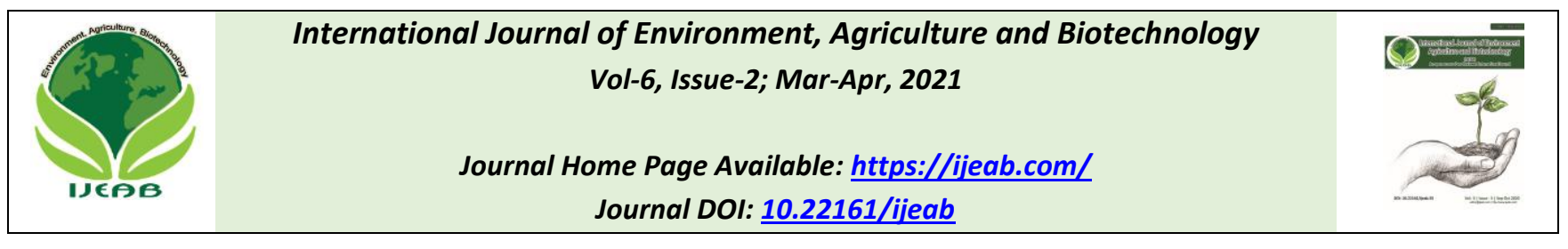

\title{
A Review on Feed Additives used in Fish Diet
}

\author{
M. K. Yadav*, A. Khati, R. S. Chauhan, P. Arya, A. Semwal
}

College of fisheries Science, G. B. Pant University of Agriculture and Technology, Pantnagar Uttarakhand, India

*Corresponding author

Received: 02 Feb 2021; Received in revised form: 19 Mar 2021; Accepted: 11 Apr 2021; Available online: 28 Apr 2021

(C)2021 The Author(s). Published by Infogain Publication. This is an open access article under the CC BY license

(https://creativecommons.org/licenses/by/4.0/).

\begin{abstract}
The feed additives are the essential compound of the fish diet. The use of feed additives in the animal's diet is a vital role to rising growth and immunity of the aquatic animals. Feed additives are substances which are added in trace amounts in fish diet it is also act as ingredients improver or preserve it. The major feed additives are act as preservatives, binders, feeding stimulants, and food colorants etc. In favor of growing aquaculture in a supportable fashion, the use of additives must be in correct amount. The requirement of additives are depends on species and their availability. Some authors exposed that the feed additive to have antimicrobial, anti-oxidative, growth promoting ability as well as it is improve the fish immune system.
\end{abstract}

Keywords-Feed additives, ingredient, oil, sustainability, digestibility, attractants, flavors etc.

\section{INTRODUCTION}

Feed additives are substances which are added in trace amounts to a diet or feed ingredient for improve or preserve it. Major feed additives are also act as preservatives, binders, feeding stimulants, and food colorants. An ingredient or combinations are added to the basic feed mix there to fulfill a specific need and usually used in micro quantities. For making the feed more attractive, palatable and digestible- attractants, flavors and digestive aids are added. Binding materials are used to prevent disintegration of feed under water column. Feed devoid of nutrient ingredients are additives that are incorporated in diets for reasons other than to offer nutrients ${ }^{[1]}$. For the most part, these compounds have little or no nutritional value, yet they are important constituents of fish feeds, increasing pellet stability, diet safety, diet flavour, and animal and fish performance and health status and influencing the quality of the final product. Nonnutritive feed ingredients include feed binders, carotenoid supplements, drugs and antibiotics, hormones, antifungal, antioxidants, fibre, flavourings, and water ${ }^{[2]}$.

\section{CLASSIFICATION OF ADDITIVES:}

According to ${ }^{[3]}$ the main objective of additives in feed is to achieve healthy and faster growth leading to higher production.

The various additives used for these purpose may be classified in to -

\section{Essential additives.}

2. Growth promoting but non-essential additives.

3. Auxiliary additives.

\subsection{Essential feed additives:}

Essential additives are supplemented in small quantities to make the formula nutritionally better balanced to promote healthy growth. Their prolonged absence in feed may cause deficiency disease ${ }^{[4]}$. Ex. Vitamins, minerals etc

\subsubsection{Vitamin}

According to ${ }^{[5]}$ studying the feed additives vitamin premixes is concentrate in which constant forms of necessary vitamins are mixed with basal feed. In the vitamin premixes choline chloride is not included because it shown to decrease the stability of other vitamins. Added at levels ranging from $0.5-4 \%$ of the diet. Vitamins are important food factors and are involved in many metabolic bio-chemical reactions of animal body.

\subsubsection{Minerals:}


Inorganic elements, calcium, phosphorus, sodium, potassium, iron, manganese, magnesium, copper, chloride, iodine, cobalt and zinc are essential minerals in the diet. Their insufficiency causes deficiency disease. Trace elements such as copper, zinc, cobalt, iodine and manganese when supplemented in the diet improve growth. Calcium and phosphorus are found in bone and exoskeleton, sodium, potassium, magnesium and chloride are associated with osmoregulation. Magnesium, Manganese and zinc are found as co-factor of metabolic enzymes. ${ }^{[6]}$

\subsubsection{Fish oils:}

Authors ${ }^{[7]}$ suggested that fish oils such as cod liver oil, sardine oil, squid oil and clam oil are rich in PUFA. Fish oil is added at 2-3 per cent level in feeds to improve growth and food conversion ratio. Oils provide dietary energy as well as fatty acids essential for aquatic animals.

\subsubsection{Fatty Acids:}

Highly unsaturated fatty acids (HUFA) such as eicosatetraenoic acid (20:5 W3) and docosahexaenoic acid (22:6 W3) may be added at $1 \%$ level to improve growth. ${ }^{[8]}$

\subsubsection{Phospholipid:}

Phospholipids such as phosphatidylcholine are essential in the diet of fish for growth and survival. Addition of 1-2 per cent of soybean lecithin in the diet promotes faster growth and improves feed conversion ratio. Phospholipids are physiologically important in transportation of lipids in the body according to ${ }^{[9]}$.

\subsubsection{Cholesterol:}

Among the steroids, cholesterol is nutritionally essential in the diet. Addition of $0.1-0.5 \%$ of cholesterol in feed enhances growth and survival. Cholesterol is present in the shrimp head waste meal ${ }^{[10]}$

\subsection{Growth promoting but non-essential additives:}

Materials derived from plant and animals, single cell proteins and some synthetic substances are used as additives in feeds for achieving faster growth and higher production. If they are not included in the feed they will not cause any deficiency disease ${ }^{[11]}$. On the other hand they are beneficial when added to feed. These are growth promoters and attractants. Ex. Plant materials, Animal materials, Single cell proteins, Antibiotics, Drug etc.

\subsubsection{Antibiotics:}

Authors ${ }^{[12]}$ suggested that antibiotics are generally found to stimulate growth of young animals rather than adults. Antibiotics show positive response in feeds formulated with vegetable proteins. Reduce or eliminate the activity of pathogens, Eliminate bacteria which produce toxins that reduce growth, Stimulate growth of beneficial micro- organisms which synthesize nutrients, Reduce microorganisms which compete with host for nutrients Increase the absorptive capacity of intestine.

\subsubsection{Drugs:}

Drugs like arsenicals and sulpha drugs are added to feed for improving growth. 3-nitro-4-hydroxy phenyl arsenic acid, para-amino-phenyl arsenic acid and its sodium salt are the arsenicals used for this purpose. Among the sulpha drugs, sulphanamides are employed. Drugs are act as tonics for animals which contribute to general wellbeing and appearance. The exact mode of action of these drugs is not known, their functions seems to be similar to that of antibiotics ${ }^{[13]}$.

\subsubsection{Hormones:}

Various natural and synthetic hormones have been used in aquaculture for-

1. Inducement of spawning,

2. Sex reversal,

3. Production of mono-sex population,

4. Growth enhancement.

Hormones responsible for fish growth are growth hormone, thyroid hormone, gonadotropin, prolactin, insulin and various steroids. Steroid hormones- androgen, estrogens and progestogens and non-steroidal hormonesthyroxin are used as growth promoters ${ }^{[14]}$.

\subsubsection{Enzyme:}

Researchers ${ }^{[15]}$ concluded that enzymes are improving the digestion of feed to the fish also can't digest and can't digest competently. Enzyme also used in the digestion of complex carbohydrates, collagen in skin and bones, and other feed constituents. Enzymes are typically denatured at temperatures above $65^{\circ} \mathrm{C}$. Thus enzyme supplements are typically spread on feeds after pelleting.

\subsubsection{Probiotics:}

Probiotics are live microbial feed supplements that stimulate fish growth by affecting the microbial flora population in the gut. Probiotic may be a single species of microorganisms or a mixture of species. The species of microorganisms present in the supplement colonizes the gut and detrimental species of microorganisms. Allowing the fish are to avoid wasting metabolic energy fighting the effects of detrimental organisms. Probiotics must be added to the feeds after pelleting ${ }^{[16]}$.

\subsubsection{Prebiotics}

Prebiotics are mostly fibers that are non-digestible food ingredients and beneficially affect the host's health by selectively stimulating the growth and activity of some genera of microorganisms in the colon, generally lactobacilli and bacteria ${ }^{[17]}$. 


\subsubsection{Synbiotics}

When Gibson introduced the concept of prebiotics he speculated on the extra benefits if prebiotics were combined with probiotics to make what he termed as Synbiotics ${ }^{[17]}$. A symbiotic product beneficially affects the host in improving the survival and implantation of live microbial dietary supplements within the alimentary canal by selectively stimulating the expansion.

\subsubsection{Phytobiotic}

The phytobiotic canister is regarded as plant-derived foodstuffs inoculation to feed in arranges to improve performance in aquatic species. Generally the plants leaves, roots, tubers, and fruits of herbs, spices and other plants also used as pytobiotics. The pytobiotics menially used to enhance the growth performance in fish and shrimp culture ${ }^{[18]}$.

\subsection{Auxiliary additives:}

According to ${ }^{[19]}$ the certain components added to feed formula act as components to the physical properties of feed. This in turn helps in better utilization of feed resulting in feed efficiency. Such additives may be considered as auxiliary additives. These are feed colour, binders, molasses and fats. Ex. Attractants, Colour, Binders, Molasses, etc

\subsubsection{Feed colorants:}

Over 300 pigments are found in various plant and animals. Carotenoids and astaxanthins are either present in some natural or as synthetic substances. Xanthophyll and carotenoids are being the most important classes of pigments. Most part xanthophyll are found in plants and carotenoid pigments are in crustaceans and in fish ${ }^{[20]}$. They are also found to improve growth and survival of fish. The function of these colors is mainly for proper pigmentation of cultured species.

\subsubsection{Binders:}

Fish feed must be strong enough to withstand normal handling and shipping without disintegration. Moreover, fish feed must be somewhat water-stable. Starch present in basic feed ingredients is gelatinize during processing and act as binder in feed. Materials such as agar-agar, carboxymethylcellulose (CMC), bentonite, guar gum, lignin sulfate, plaster of Paris, polyvinyl alcohol, sodium alginate and wheat gluten are used as binder. Used at 2 to $8 \%$ level for higher stability of pellets ${ }^{[21]}$.
Addition of molasses to feed often helps in smooth pelleting of feed. Also improves its palatability. It is also a good source of energy in feed ${ }^{[22]}$.

\section{IMPORTANCE OF FEED ADDITIVES}

1. The feed additives are used for their importance in fish feed and their outcome on the stability and texture of the fish diet.

2. The feed additives for example the pigments increase the economic otherwise nutritional value of fish.

3. Additives are increases fish growth, feed conversion ratio, protein efficiency ratio, and specific growth.

4. Feed additives are also act as antimicrobial activity, ant-oxidative effects, it enhances the feed palatability, improves the gut functions.

\section{AN OVERVIEW ON THE RECENT STUDY RELATING THE INCORPORATION OF FEED ADDITIVES IN FISH DIET}

Authors ${ }^{[23]}$ suggested that the new aspects of using some safe feed additives on alleviated imidacloprid toxicity in farmed fish: a review. Investigators was ${ }^{[24]}$ reviewed that the fish and shellfish are precious and cheap sources of Omega fatty acids and several other important nutrients for human consumption. There is critical need to study further on novel feed additives similar to inclusion of herbs on fish feeds which decrease feed expenditure, highest digestibility and prevention of remaining effects of hormones and antibiotics on fish muscles which in returns have effects on human that consumes them. The fishing have also been connected with a fast increase in fish consumption, as well as the presence of omega- 3 and omega- 6 fatty acids, which are essential for humans other than high quality and feed additives. According to ${ }^{[25]}$ the feed contain useful feed additives encourage the growth and physical condition of tilapia, get better their immune systems, and encourage physiological benefits away from traditional feeds. The feed additives such as probiotics, prebiotics, phytogenic substances, immune-stimulants, enzymes, hormones, mycotoxin binders, organic acids etc. are best functional feed additives.

Authors ${ }^{[26]}$ reviewed the feed additives in aqua feeds. Aquaculture trade show swift growth in our country. The reason of the use of feed additives in aquaculture is to raise efficiency, superiority and income. On the other hand, due to ecosystem dilapidation, environmental pollution and leaving residues of the feed additive to the environment, a judgment alternative feed additive has been mandatory. Performing additional researches intended at raising the 
productivity of fish through by additives will allow the appropriate fish feed. The according to ${ }^{[27]}$, ${ }^{[28]}$, ${ }^{[29]}$ has been analyzed some researches about enzymes, herbal feed additives and probiotics used as an additive in fish feed. Those feed additives are increase the feed palatability, feed colour, and feed nutrient quality as well as improve the feed digestibility and ultimately enhance the fish production.

Researchers ${ }^{[30]}$ have evaluated the feed additives in animal diets be able to work as chemo preventive agents, which have the possible to reduce the toxicity risk of several pollutants and detoxification of activated metabolites. Understanding the interior act mechanisms of different protected feed additives could lead to the novel therapeutic approaches for acute and chronic pesticide toxicity. According to authors ${ }^{[31]},{ }^{[32]},{ }^{[33]}$, [34] studding the fish nutrition should be cautiously analyzed and there is a requirement to investigate for the novel feed additives and supplements which make sure low feed price, maximum digestibility with least side effects and high feed conversion ratio. Authors are [35] studied on the highquality feed is arranged from appropriate and essential feed additives. Useful feed additives not only pick up the growth performance of the fishes other than also get better the health performance of the fishes. These useful feed additives include prebiotics, probiotics, seaweeds, mushrooms, microalgae, enzymes, organic acids, mycotoxin binders, photogenic or phytobiotic compounds and yeasts. Researchers ${ }^{[36]}$ has reviewed on utilize of antibiotics in the aqua feeds to moderate infectious diseases and to improve growth performance is commonly practiced. A moment ago, the prophylactic use of antibiotics and chemotherapies have been criticized which ultimately led to their ban in aquaculture by law on several countries. One possible replacement for antibiotics in aqua feeds is the use of useful feed additives. The present review is a whole and an efficient collection of the available works on different feed additives, their examples including probiotics, prebiotics, synbiotics, immunostimulants, organic acids, nucleotides and medicinal herbs.

According to reviewers ${ }^{[37]}$ has reviewed on application of probiotic, prebiotic and synbiotic for sustainable development of aquaculture. The review summarizes and discusses the effects of probiotic, prebiotic or synbiotic administration on growth performance, stress tolerance, intestinal microbiota, immune response and health of aquatic organisms, [38] has evaluated the growth and metabolism of Labeo rohita (Hamilton, 1822) fingerlings feed with Aloe vera supplementation diet. They found a significant role of Aloe vera as an herbal growth advertiser when varied in the basal diet of groundnut oil cake, rice bran and wheat flour for $L$. rohita fingerling. The incorporation of Aloe vera in fish diet does not show adverse impact on health of L. rohita and it is environment friendly. On the basis of the results obtained in the study, it was concluded that Aloe vera supplementation @ 400g/kg diet has paramount importance in enhancing the growth performance and metabolism. The researches ${ }^{[38]}$ studied on the role of Pedalium murex in the enhancement of growth, metabolism and immunity of Labeo rohita (Hamilton, 1822) fingerlings. They concluded that a Pedalium murex extract supplemented diet has the significant role in improving the growth of $L$. rohita besides its ability to enhance metabolism and immunity of the fish. The optimum dose $(0.08 \mathrm{gm} / 100 \mathrm{gm} \mathrm{diet})$ in the feed of $L$. rohita need to be further tested under field condition so that the Pedalium murex may be recommended for the commercial aquaculture.

Authors were ${ }^{[39]}$ studied on the effect of ethanolic extract of Mucuna pruriens on growth, metabolism and immunity of Labeo rohita (Hamilton, 1822) fingerlings. They reported that the Mucuna pruriens extract supplemented diet has significant role in improving growth of L. rohita besides its ability to enhance metabolism and immunity, ${ }^{[38]}$ studied on the growth, metabolism and haematological parameters of Labeo rohita (Hamilton, 1822) fingerlings fed with herbal supplemented diet. They found that Pedalium murex and Mucuna pruriens combination (1:1) extract supplemented diet has significant role in improving growth of L. rohita. Besides, it has ability to enhance metabolism and immunity of the fish. Authors ${ }^{[40]}$ studied on the effects of varying levels of Moringa oleifera leaf meal diet on growth performance, hematological indices and biochemical enzymes of African catfish Clarias gariepinus (Burchell 1822). The authors are recommended that the fish is a essential source of high-quality protein, providing approximately 16 per cent of the animal protein consumed by the world's population (FAO 1997). It is a mainly vital protein source in regions where livestock is relatively scarce. The investigators ${ }^{[41]}$ have studied the nutritive importance of water hyacinth (Eichhornia crassipes) leaf meal in mix diets for rohu, Labeo rohita (Hamilton, 1822) fingerlings after fermentation through two bacterial strains isolated from fish gut. They suggested that 40 per cent of fish meal can be replaced with water hyacinth leaf meal fermented with fish gut bacteria devoid of any undesirable effect on growth of the fish to produce cost effective formulated fish feed. The nutritional properties of Mucuna utilis seed meal and its consumption in the diet of Clarias gariepinus (Burchell, 1822), [42] concluded on that toasting significantly enhanced the nutritional quality of this original feedstuff, allowing better consumption at up to $200 \mathrm{~g} / \mathrm{kg}$ inclusion level in the diet of 
African catfish $C$. gariepinus, ${ }^{[44]}$ studied on the effect of natural $\beta$-carotene from-carrot (Daucus carota) and Spinach (Spinacia oleracea) on colouration of an ornamental fish - swordtail (Xiphophorus hellerii). They concluded that dietetic supplementation of carrot at the rate $1.82 \mathrm{~g} / 100 \mathrm{~g}$ of diet and spinach at the rate of 1.33 $\mathrm{g} / 100 \mathrm{~g}$ of diet may be used for pretty the orange coloration in swordtail (Xiphophorus hellerii). Because synthetic carotenoid are expensive, cheap and readily available natural carotenoid sources such as carrot and spinach can be incorporated into the diet to enhance better coloration in swordtail, ${ }^{[43]}$ studied on the valuable effects of probiotics in aquaculture. The uses of probiotics in aquaculture have exposed many valuable impacts on fish health by decreeing the risk of diseases, which also measured as a vital step in maintaining sustainable aquaculture. While the favorable effect of probiotics is well recognized, the huge scale use of probiotics in the development of commercial aquaculture.

The effects of fish oil substitution with sunflower oil in diet of juvenile Catla catla (Ham) on growth performance and feed utilization. Authors [ ${ }^{45}$ results clearly revealed that sunflower oil could be partially 50 per cent replaced without any adverse effect on the growth performance. The significance of oils in fish diet has been reviewed by [2] they suggested that the oils are cheap sources of essential fatty acid. The uses of dietary oils in accurate quantities as per the required of indivisible animal best the growth and body composition are must. Further they suggested that the oils are beneficial for fish because there antimicrobial, anti-oxidative; growth promoting ability and also as enhances of feed palatability, digestibility \& binding capacity.

\section{CONCLUSION}

The various additives used for these purpose may be classified in to essential additives, growth promoting but non-essential additives, and auxiliary additives. Major feed additives; preservatives, binders, feeding stimulants and food colorants and they are incorporated in feed to achieve healthy and faster growth leading to higher production. Finally it can be concluded that feed additive are added in feed to enhance growth and production, to make diet more attractive, more palatable and digestible- attractants, flavors and increase digestibility.

\section{REFERENCES}

[1] Dawood, M.A., Koshio, S. and Esteban, M.Á.,. Beneficial roles of feed additives as immunostimulants in aquaculture: a review. Reviews in Aquaculture, 2018; 10(4),.950-974.

[2] Yadav, M.K., Ojha, M.L., Keer, N.R. and Yadav, A. An overview on the use of oil in fish diet. 2019; 7(1): 883-885.

[3] Soetan, K.O., Olaiya, C.O. and Oyewole, O.E.. The importance of mineral elements for humans, domestic animals and plants-A review. African journal of food science, 2010; 4(5), .200-222.

[4] Luo, X.G., Ji, F., Lin, Y.X., Steward, F.A., Lu, L., Liu, B. and $\mathrm{Yu}, \mathrm{S} . \mathrm{X}$. Effects of dietary supplementation with copper sulfate or tribasic copper chloride on broiler performance, relative copper bioavailability, and oxidation stability of vitamin E in feed. Poultry Science, 2005; 84(6), .888-893.

[5] Demott, W. and Müller-Navarra, D.O.R.T.H.E. The importance of highly unsaturated fatty acids in zooplankton nutrition: evidence from experiments with Daphnia, a cyanobacterium and lipid emulsions. Freshwater Biology, 1997; 38(3), .649-664.

[6] Kyaw, K., Koshio, S., Ishikawa, M., Yokoyama, S., Kikuchi, K., Laining, A., Muraoka, Y. and Akimoto, Y. Effects of different levels of dietary mussel phospholipids on the performances of Juvenile Kuruma Shrimp Marsupenaeus japonicus Bate. Aquaculture Science, 2010; 58(1),.75-83.

[7] Deng, Junming, Bin Kang, Linli Tao, Hua Rong, and Xi Zhang. "Effects of dietary cholesterol on antioxidant capacity, non-specific immune response, and resistance to Aeromonas hydrophila in rainbow trout (Oncorhynchus mykiss) fed soybean meal-based diets." Fish \& shellfish immunology 2013; 34, 1: 324-331.

[8] Nasseri, A.T., Rasoul-Amini, S., Morowvat, M.H. and Ghasemi, Y. Single cell protein: production and process. American Journal of food technology, 2011; 6(2).103-116.

[9] Heo, J.M., Opapeju, F.O., Pluske, J.R., Kim, J.C., Hampson, D.J. and Nyachoti, C.M. Gastrointestinal health and function in weaned pigs: a review of feeding strategies to control post-weaning diarrhoea without using in-feed antimicrobial compounds. Journal of animal physiology and animal nutrition, 2013; 97(2),207-237.

[10] Buffum, J. Pharmacosexology: the effects of drugs on sexual function-a review. Journal of Psychoactive Drugs, 1982; 14(1-2).5-44.

[11] Apenuvor, T,. Crossing, Sex reversal and reproductive capacity of two populations of Sarotherodon Melanotheron (Cichlidae) from the Central Region of Ghana (Doctoral dissertation, University of Cape Coast) 2014.

[12] Hardy, R.W. and Barrows, F.T,. Diet formulation and manufacture. In Fish nutrition 2003;. 505-600

[13] Fiala, R.J., Scott, T.L. and Wright, K.N., Tate and Lyle Ingredients Americas LLC, Molasses impregnated bagasse pith animal feed. U.S. Patent 1977; 4,012,535.

[14] Naiel, M.A., Shehata, A.M., Negm, S.S., Abd El-Hack, M.E., Amer, M.S., Khafaga, A.F., Bin-Jumah, M. and Allam, A.A., The new aspects of using some safe feed 
additives on alleviated imidacloprid toxicity in farmed fish: a review 2020; Reviews in Aquaculture.

[15] Strobel, C., Jahreis, G. and Kuhnt, K., Survey of n-3 and n6 polyunsaturated fatty acids in fish and fish products. Lipids in health and disease, 2012; 11(1), .1-10.

[16] Kavita. R. Pandey, Suresh. R. Naik, and Babu. V. Vakil, Probiotics, prebiotics and synbiotics- a review. J Food Sci Technol. 2015 Dec; 52(12): 7577-7587.

[17] DeVrese, Schrezenmeir, J. M., Heller, K.J., and Bockelmann, W., Cheese and Its Potential as a Probiotic Food. Handbook of fermented functional foods.

[18] Jana, P., Karmakar, S., Roy, U., Paul, M. and Bera, A.K.S.K.K., Phytobiotics in aquaculture health management: A review. Journal of Entomology and Zoology Studies, 2018; 6(4), .1422-1429.

[19] Shahidi, S., Mehrpour, O., Sadeghian, R., Asl, S.S. and Komaki, A., Alteration level of hippocampus expression and long-term potentiation upon microinjection of hydrochloride in a rat model of methamphetamine relapse. Brain research bulletin, 2019; 148,.18-24.

[20] Wagde, M.S., Sharma, S.K., Sharma, B.K., Shivani, A.P. and Keer, N.R. Effect of natural $\beta$-carotene from-carrot (Daucus carota) and Spinach (Spinacia oleracea) on colouration of an ornamental fish - swordtail (Xiphophorus hellerii). Journal of Entomology and Zoology Studies ;2018; 6(6): 699-705.

[21] Hardy, R.W. and Barrows, F.T., Diet formulation and manufacture. In Fish nutrition 2003; 505-600, Academic Press.

[22] Fiala, E.S., Investigations into the metabolism and mode of action of the colon carcinogens 1, 2-dimethylhydrazine and azoxymethane. Cancer, 1977; 40.(5),2436-2445.

[23] Naiel, M.A., Shehata, A.M., Negm, S.S., Abd El-Hack, M.E., Amer, M.S., Khafaga, A.F., Bin-Jumah, M. and Allam, A.A., The new aspects of using some safe feed additives on alleviated imidacloprid toxicity in farmed fish: a review. Reviews in Aquaculture, 2020; 12(4),.2250-2267.

[24] Strobel, G.A.,. Bioprospecting-fuels from fungi. Biotechnology letters, 2015; 37(5),.973-982.

[25] Alemayehu, T.A., Geremew, A. and Getahun, A., The role of functional feed additives in tilapia nutrition. Fisheries and Aquaculture Journal, (2018); 9(2),.1g-1g.

[26] Dalbir, S.P., Roopma, G., Ritu, K., Vaini, G. and Shivalika, $\mathrm{R}$,. Effect of fish oil substitution with sunflower oil in diet of juvenile Catla catla (Ham) on growth performance and feed utilization. Journal of Fisheries \& Livestock Production, 2015; 1-3 : 2332-2608.

[27] Bai SC, Katya K, Yun H ,. Additives in aquafeed: an overview. In feed and Feeding Practices in Aquaculture,.2015; 171-202.

[28] Barrows FT, Hardy RW,. Feed Additives. In: Encyclopedia of Aquaculture, 2000; : 336-340.

[29] Carocho, M., Barreiro, M.F., Morales, P. and Ferreira, I.C., Adding molecules to food, pros and cons: A review on synthetic and natural food additives. Comprehensive reviews in food science and food safety, 2014; 13(4),.377399.
[30] Bharathi, S., Antony, C., Cbt, R., Arumugam, U., Ahilan, B. and Aanand, S., Functional feed additives used in fish feeds. International Journal of Fisheries and Aquatic Studies, 2019; 7(3),.44-52.

[31] Bimbo, A.P., Crowtber, B,. Fish meal and oil: Current uses. J1 of Am Chem Soc 1992; 69, 221-227.

[32] Carocho, M., Morales, P. and Ferreira, I.C., Natural food additives: Quo vadis. Trends in food science \& technology., 2015; 45(2),.284-295.

[33] Dada AA ., Effect of herbal growth promoter feed additive in fish meal on the performance

[34] of Nile Tilapia (Oreochromis niloticus (L.). Egypt Acad J Biolog Sci 4: 111-117.

[35] Gupta, S., Banerjee, S,. Food, Feeding Habit and Reproductive Biology of Tire-track Spiny Eel (Mastacembelus armatus): A Review. J Aquac Res Development ,. 2016,.7, 429.

[36] Dada, A.A., Improvement of tilapia (Oreochromis niloticus Linnaeus, 1758) growth performance fed three commercialfeed additives in diets. Journal of Aquaculture Research and Development 2015; 6, 325-327.

[37] Bishnoi, K., Ojha, M.L., Sharma,S.K., and Saini,V.P., Evaluation of growth and metabolism of Labeo rohita (Hamilton, 1822) fingerlings with Aloe vera supplementation diet. Journal of Entomology and Zoology Studies,. 2017; 5(4): 1595-1599.

[38] Ojha, M.L., Chadha, N.K., Saini, V.P., Damroy, S., Chandraprakash and Sawant,P.B., Effect of ethanolic extract of Mucuna pruriens on growth, metabolism and immunity of Labeo rohita (Hamilton, 1822) fingerlings. International Journal of Fauna and Biological Studies, 2014; 5:01-09.

[39] Ojha, M.L., Chadha, N.K., Saini, V.P., Damroy, S., Chandraprakash and Sawant,P.B,. Role of Pedalium murex in the enhancement of growth, metabolism and immunity of Labeo rohita (Hamilton, 1822) fingerlings. International Journal of Fauna and Biological Studies, .2014.,1 (6): 7077.

[40] Bello, N.O. and Nzeh, G.C., Effect of varying levels of Moringa oleifera leaf meal diet on growth performance, haematological indices and biochemical enzymes of African catfish, Clarias gariepinus (Burchell, 1822). Elixir Aquaculture, 2013. 57:14459-14466.

[41] Saha, S. and Ray, A.K. Evaluation of nutritive value of water hyacinth (Eichhornia crassipes) leaf meal in compound diets for rohu, Labeo rohita (Hamilton, 1822) fingerlings after fermentation with two bacterial strains isolated from fish gut. Turkish Journal of Fisheries and Aquatic Sciences, .2011; 11(2):199-207.

[42] Okomoda, V.T., Tiamiyu, L.O. and Akpan, I.S,. Nutritional evaluation of toasted Mucuna utilis seed meal and its utilization in the diet of Clarias gariepinus (Burchell, 1822). Journal of Applied Aquaculture, 2017; 29(2):167182.

[43] Akter, N., Parvez, I., and Patwary,Z.P'., Beneficial effects of probiotics in aquaculture. International Journal of Fisheries and Aquatic Studies ; 2016; 4(5): 494-499. 
[44] Ali, A. S., Feed additives for growth promotion in shrimp. CIBA. Fishing chimes., 1995; 21-23.

[45] Wagde, M.S., Sharma, S.K. and Sharma, B.K., Effect of natural $\beta$-carotene sources-Carrot (Daucus carota) and Spinach (Spinacia oleracea) on the growth of an ornamental fish - sword tail (Xiphophorus hellerii). Journal of Entomology and Zoology Studies ; 2018; 6(5): 21122115.

[46] Dalbir, S.P., Roopma, G., Ritu, K., Vaini, G. and Shivalika, R., Effect of fish oil substitution with sunflower oil in diet of juvenile Catla catla (Ham) on growth performance and feed utilization. Journal of Fisheries \& Livestock Production. 2015; 1-3: 2332-2608.

[47] Barthod, J., Rumpel, C. and Dignac, M.F.,Composting with additives to improve organic amendments. A review. Agronomy for sustainable development, 2018; $38(2), .17$.

[48] Winkler, H.C., Notter, T., Meyer, U. and Naegeli, H., Critical review of the safety assessment of titanium dioxide additives in food. Journal of nanobiotechnology., 2018; 16(1), 51.

[49] Winter, R., A consumer's dictionary of food additives: Descriptions in plain English of more than 12,000 ingredients both harmful and desirable found in foods. Crown Archetype., 2009.1,236. 